\title{
Cholesteryl Ester Transfer Protein Gene and Effectiveness of Lipid Lowering of Atorvastatin
}

\author{
Genovefa Kolovou $^{1, *}$, Constantinos Mihas ${ }^{2}$, Katherine Anagnostopoulou ${ }^{3}$ Vana Kolovou ${ }^{3}$, \\ Vasiliki Giannakopoulou ${ }^{1}$, Peggy Kostakou ${ }^{1}$, Marianna Stamatelatou ${ }^{1}$, Sophie Mavrogeni ${ }^{1}$, \\ Dimitrios Degiannis ${ }^{3}$ and Dimitri P. Mikhailidis ${ }^{4}$ \\ ${ }^{I} I^{\text {st }}$ Cardiology Department, Onassis Cardiac Surgery Center Athens, Greece \\ ${ }^{2}$ Internal Medicine Department, Kimi General Hospital, Kimi, Greece \\ ${ }^{3}$ Molecular Immunology Laboratory, Onassis Cardiac Surgery Center Athens, Greece \\ ${ }^{4}$ Department of Clinical Biochemistry (Vascular Disease Prevention Clinics), Royal Free Hospital campus, University \\ College London Medical School, University College London (UCL), London, UK
}

\begin{abstract}
Cholesteryl ester transfer protein (CETP) plays a key role in lipid metabolism. Thus, variations in the CETP gene may be clinically relevant.

Newly started atorvastatin users $(\mathrm{n}=212)$ were genotyped for CETP genetic variants (TaqIB and I405V). Homozygotes for B1 allele of TaqIB polymorphism had lower plasma high density lipoprotein cholesterol (HDL-C) compared with $\mathrm{B} 1 \mathrm{~B} 2$ or B2B2 genotypes ( $\mathrm{p}=0.03$, for each). Homozygotes for I allele of I405V polymorphism had lower plasma HDL-C compared with IV or VV genotypes ( $\mathrm{p}=0.001$, for each). In the whole population, the B1 carriers increased HDL-C levels by $4 \%$ after atorvastatin treatment, compared with $\mathrm{B} 2$ carriers, where a $4 \%$ decrease occurred $(\mathrm{p}=0.03)$. Also homozygotes for B1 allele decreased triglyceride levels to a lesser, though not significant, degree compared to B1B2 or B2B2 genotypes.
\end{abstract}

CETP TaqIB or I405V polymorphisms seem to modify the lipid lowering response to atorvastatin treatment. This knowledge may help design more effective hypolipidaemic treatment.

Keywords: Atorvastatin, cholesteryl ester transfer protein, genetic polymorphisms, lipid profile.

\section{INTRODUCTION}

Cholesteryl ester transfer protein (CETP) plays a major role in modifying lipoprotein particles by mediating the transfer of cholesteryl esters from high-density lipoprotein (HDL) particles to apolipoprotein B-containing lipoproteins in exchange for triglycerides (TG) [1]. The CETP gene encompasses 16 exons, on chromosome 16q12-16q21; several CETP polymorphisms have been identified including I405V and TaqIB which are associated with reduced CETP mass and increased HDL cholesterol (HDL-C) [2]. I405V results in a single amino acid change at codon 405 in exon 14; in several studies, the I405V allele was associated with lower CETP levels [2]. TaqIB has been shown to be a silent base change affecting the 277th nucleotide in the first intron of the gene [3]. The B2 allele (absence of the TaqI restriction site) at this polymorphic site has been associated in normolipemic subjects with increased HDL-C levels and decreased CETP activity and levels [4].

HMG-CoA (3-hydroxy-3-methylglutaryl coenzyme A) reductase inhibitors (statins) are the main drugs used to

\footnotetext{
*Address correspondence to this author at the Onassis Cardiac Surgery Center 356 Sygrou Ave 17674 Athens, Greece; Tel: +30 210 9493520;

Fax: +30 210 9493336; E-mail: genovefa@kolovou.com
}

reduce plasma low density lipoprotein cholesterol (LDL-C) levels. Also, statins can be administrated to subjects with high triglyceride (TG) and low HDL-C levels (a dyslipidaemic combination which often coexists) $[5,6]$. There is considerable variation in the response to statin treatment [7]. Although most subjects derive a $30 \%$ to $50 \%$ reduction in LDL-C cholesterol with statin therapy, there is wide variation in the dose response. Environmental and genetic factors may contribute to this variability. In line with our previous work [8], we assessed whether 2 common polymorphisms of CETP (I405V and TaqIB) influence the lipid response after treatment with atorvastatin.

\section{SUBJECTS AND METHODS}

\section{Subjects}

Ad hoc power analysis showed that in order to detect two-sided differences higher than $20 \%$ in one of the main outcome variables (TG) before and after treatment with atorvastatin, achieving statistical power equal to $90 \%$ at a significance level less than 0.05 , we had to recruit at least 190 individuals for each group. Due to unexpected conditions, more people entered the study, potentially increasing its statistical power. We genotyped 212 Greek unrelated hypercholesterolaemic subjects (141 men and 71 women) aged 
$56.8( \pm 12.9)$ years with primary hypercholesterolemia. Additional inclusion criteria included a stable medication (patients with coronary artery disease were on cardioselective $\beta$ blockers and aspirin, patients with hypertension were on angiotensin converting enzyme inhibitors) regimen and diet for at least 4 weeks prior to study screening. Subjects with a history of stroke, renal diseases, and diabetes mellitus were excluded from the study. The subjects were assigned to atorvastatin treatment for at least 6 months. The dose of atorvastatin (10-40 mg/day) was adjusted according to the National Cholesterol Education Program Adult Treatment Panel III (NCEP ATP III) treatment goal for LDL-C based on risk category (LDL-C $<130 \mathrm{mg} / \mathrm{dl},<100 \mathrm{mg} / \mathrm{dl}$ or $<70$ $\mathrm{mg} / \mathrm{dl} ;<3.4 \mathrm{mmol} / \mathrm{l},<2.6 \mathrm{mmol} / \mathrm{l}$ or $<1.8 \mathrm{mmol} / \mathrm{l}$ ) [9].

Subjects were further divided according to their baseline HDL-C levels into groups: 1. Low HDL group [HDL-C <40 $\mathrm{mg} / \mathrm{dl}(<1 \mathrm{mmol} / \mathrm{l})]$ and 2 . High HDL group $[\mathrm{HDL} \geq 40$ $\mathrm{mg} / \mathrm{dl}(\geq 1 \mathrm{mmol} / \mathrm{l})]$. All subjects were started on atorvastatin as the only lipid lowering drug. Exclusion criteria were heavy drinking as well as liver and renal disease. Our Institutional Review Board approved the study.

\section{DNA Analysis and Determination of Blood Lipids and Glucose}

The CETP (TaqIB, I405V) polymorphisms were detected by using Polymerase Chain Reaction and Restricted Fragment Length Polymorphism analysis as previously described $[10,11]$. The measurement of total, LDL-C, HDL-C and TG was performed as described elsewhere [10]. Briefly, total cholesterol, TG and HDL-C levels were measured using enzymatic colorimetric methods, on a Roche Integra Biochemical analyzer, with commercially available kits (Roche Diagnostics Gmbh, Hannheim, Germany). The serum LDLC levels were calculated using the Friedewald formula in subjects with TG levels $<400 \mathrm{mg} / \mathrm{dl}$.

\section{Statistical Analysis}

All continuous variables are shown as median and interquartile range $\left(25^{\text {th }}, 75^{\text {th }}\right.$ percentile) since they all (except for age and BMI) deviated from normality. However, for facilitation reasons, age and BMI are also treated as non-normally distributed variables. All categorical variables are presented as relative (percentage) frequencies. The Kruskal-Wallis $\mathrm{H}$ statistic was used to compare the continuous variables among the 3 genotype groups, while the Mann-Whitney U test was used to compare the continuous variables between the 2 groups of carriers. Wilcoxon signed-rank test was used to evaluate the differences before and after treatment. The Pearson's chi-square test was used to evaluate any association between categorical variables and genotypes/alleles. The differences in total cholesterol, TGs, HDL-C and LDL-C before and after atorvastatin treatment were also described as $\%$ difference, based on the following rule: $\%$ difference $=$ [(variable after-variable before)/variable before]*100. All tests were 2-sided at a significance level of $p<0.05$. Data were analyzed using STATA ${ }^{\mathrm{TM}}$ (Version 9.0, Stata Corporation, College Station, TX 77845, USA).

\section{Results}

\section{Genotype and Allele Frequencies in the Whole Cohort}

The genotype frequency of the TaqIB and I405V polymorphisms was B1B1 31.9\%, B1B2 54.3\%, B2B2 $13.8 \%$ and II $45.0 \%$, IV $40.8 \%$, VV $14.2 \%$, respectively. The B1 and B2 alleles were found at frequencies of $58.9 \%$ and $41.1 \%$, respectively, while the I and $\mathrm{V}$ alleles were found at $65.5 \%$ and $34.5 \%$, respectively.

\section{Baseline Lipid Profile According to Genotype in the Whole Cohort}

\section{TaqIB Polymorphism}

Homozygotes for B1 allele had lower plasma HDL-C compared with B1B2 and B2B2 genotype ( $\mathrm{p}=0.03$, for each, Table 1). Accordingly, the B2 allele was associated with higher HDL-C levels compared with B1 allele $(\mathrm{p}=0.02$, Table 2). Total cholesterol, LDL-C and TG levels did not vary significantly among TaqIB genotypes (Table $\mathbf{1}$ ).

\section{I405V Polymorphism}

The IV genotype was associated to higher HDL-C levels compared with II genotype $(\mathrm{p}=0.001)$. The $\mathrm{V}$ allele was associated woth higher HDL-C levels compared with I allele $(\mathrm{p}=0.04)($ Table 2).

Table 1. Baseline Lipid Profile of the Study Cohort Based on TaqIB or I405V Genotypes

\begin{tabular}{|c|c|c|c|c|c|c|c|c|}
\hline & B1B1 (n=67) & B1B2 $(n=114)$ & B2B2 $(n=29)$ & $\mathbf{p}$ & II (n=95) & IV $(n=86)$ & $\mathbf{V V}(\mathbf{n}=\mathbf{3 0})$ & $\mathbf{p}$ \\
\hline Age (years) & $59(21)$ & $59(18)$ & $54(23)$ & 0.51 & $56(21)$ & 59(19) & $61(18)$ & 0.25 \\
\hline BMI (kg/m2) & $26(3)$ & $27(5)$ & $26(4)$ & 0.57 & $27(4)$ & $26(5)$ & $27(4)$ & 0,48 \\
\hline $\mathrm{TG}(\mathrm{mg} / \mathrm{dl})$ & $175(101)$ & $144(122)$ & 153(179) & 0.46 & $167(123)$ & $144(139)$ & 147(99) & 0.29 \\
\hline HDL-C (mg/dl) & $40(15)$ & $45(19)$ & $49(24)$ & 0.04 & $41(17)$ & $48(21)$ & $45(18)$ & 0.004 \\
\hline LDL-C (mg/dl) & $188(49)$ & $195(88)$ & $205(81)$ & 0.62 & $185(81)$ & $190(67)$ & $194(88)$ & 0.52 \\
\hline
\end{tabular}

Continuous variables are shown as median and interquartile range. Kruskal-Wallis H statistic was used to compare the continuous variables among the three genotype groups. CETP: cholesteryl ester transfer protein, BMI: body mass index, HDL-C: high-density lipoprotein cholesterol, LDL-C: low-density lipoprotein cholesterol, TC: total cholesterol, TG: triglycerides.

For TC, HDL and LDL, to convert from $\mathrm{mg} / \mathrm{dl}$ to $\mathrm{mmol} / \mathrm{l}$ divide by 38.8 . For TG, to convert from $\mathrm{mg} / \mathrm{dl}$ to $\mathrm{mmol} / \mathrm{l}$ divide by 88.6 
Table 2. Baseline Lipid Profile of the Study Cohort Based on TaqIB or I405V Alleles

\begin{tabular}{|c|c|c|c|c|c|c|}
\hline & B1 & B2 & $\mathbf{p}$ & $\mathbf{I}$ & $\mathbf{V}$ & $\mathbf{p}$ \\
\hline BMI (kg/m2) & $27(4)$ & $26(4)$ & 0.91 & $27(4)$ & $27(4)$ & 0.82 \\
\hline HDL-C (mg/dl) & $42(19)$ & $48(19)$ & 0.02 & $43(20)$ & $48(19)$ & 0.04 \\
\hline LDL-C (mg/dl) & $190(61)$ & $197(81)$ & 0.41 & 190(77) & 194(74) & 0.26 \\
\hline
\end{tabular}

All continuous variables are shown as median and interquartile range. Mann-Whitney U statistic was used to compare the continuous variables among the three genotype groups. CETP: cholesteryl ester transfer protein, BMI: body mass index, HDL-C: high-density lipoprotein cholesterol, LDL-C: low-density lipoprotein cholesterol, TC: total cholesterol, TG: triglycerides. B1: variant allele-carrying genotypes (B1B1, B1B2), B2: variant allele-carrying genotypes (B2B2, B1B2), I: variant allele-carrying genotypes (II, IV), V : variant allele-carrying genotypes (VV, VI). For TC, HDL and LDL, to convert from $\mathrm{mg} / \mathrm{dl}$ to $\mathrm{mmol} / \mathrm{l}$ divide by 38.8 . For TG, to convert from $\mathrm{mg} / \mathrm{dl}$ to $\mathrm{mmol} / \mathrm{l}$ divide by 88.6 .

Baseline lipid profile according to genotype in Low HDL group and High HDL group.

\section{$\underline{\text { TaqIB Polvmorphism }}$}

The $\mathrm{B} 1$ allele was more frequent in Low HDL group than in High HDL group (64.1\% vs $53.4 \%$, $\mathrm{p}=0.05$ ), while the B2 allele frequency was higher in High HDL group compared with Low HDL group (46.6\% vs 35.9\%, $\mathrm{p}=0.05$ ).

In Low HDL group, B1B2 subjects or B2 allele carriers had higher total cholesterol than B1B1 subjects $(\mathrm{p}=0.03)$ or B1 allele carriers $(\mathrm{p}=0.01)$.

In High HDL group, no significant associations were found between the TaqIB polymorphism and baseline lipid profile.

\section{I405V Polymorphism}

The II genotype was more frequent in Low HDL group compared to High HDL group (54.7\% vs $37.3 \%, \mathrm{p}=0.02)$, while the IV genotype frequency was higher in High HDL group compared with Low HDL group (48.2\% vs $31.3 \%$, $\mathrm{p}=0.03)$.

\section{Effect of Atorvastatin on Lipid Profile in the Whole Cohort and Both Groups}

Total cholesterol, LDL-C and TG levels were significantly decreased after atorvastatin administration $(-34.4 \%$, $41.2 \%$ and $-28.5 \%$, respectively; $\mathrm{p}<0.001$ for each). The HDL-C slightly increased though not significantly $2.8 \%$ $(\mathrm{p}=0.46)$.

The changes in total cholesterol, HDL-C, LDL-C and TG levels were:-37.0\% $(\mathrm{p}<0.001),+12.9 \%(\mathrm{p}<0.001),-40.1 \%$ $(\mathrm{p}<0.001),-38.1 \%(\mathrm{p}<0.001)$, respectively in the Low HDL group and $-30.9 \%(\mathrm{p}<0.001),-8.3 \% \quad(\mathrm{p}=0.001),-43.2 \%$ $(\mathrm{p}<0.001),-15.2 \%(\mathrm{p}<0.001)$, respectively in the High HDL group.

\section{Effect of Atorvastatin Treatment According to Genotype of the Whole Cohort}

The B1 carriers increased HDL-C levels by $4 \%$ after atorvastatin treatment, compared with $\mathrm{B} 2$ carriers, where a
$4 \%$ decrease was found $(\mathrm{p}=0.03)$. Also homozygotes for $\mathrm{B} 1$ allele decreased TG levels in a lesser, though not significant, degree compared with B1B2 or B2B2 genotypes [20.6\%, $35.8 \%$ or $29.1 \%$, respectively (all 3 decreases significant: $\mathrm{p}<0.001, \mathrm{p}=0.40$ for in-between comparison)].

\section{Association of the I405V or TaqIB Variants with Effective-} ness of Atorvastatin in Low and High HDL Group

B2 carriers from Low HDL group had greater decrease of total cholesterol compared with B1 carriers (-120 (44) mg/dl vs $-100(58) \mathrm{mg} / \mathrm{dl}, \mathrm{p}=0.02$ ), Table 3. Also, B2 carriers from the Low HDL group had greater decrease of TG compared with $\mathrm{B} 1$ carriers $(-45 \%$ vs. $-37 \%, \mathrm{p}=0.02)$.

In the High HDL group, LDL-C showed greater decrease in subjects with II genotype compared with those with IV genotype $[-108 \mathrm{mg} / \mathrm{dl}(-47.2 \%)$ vs $-79 \mathrm{mg} / \mathrm{dl} \quad(-37.1 \%)$, $\mathrm{p}=0.006]$.

\section{DISCUSSION}

We evaluated whether the common CETP TaqIB or I $405 \mathrm{~V}$ gene polymorphism was associated with differentiation of the plasma lipid profile and involvement of the atorvastatin effectiveness on lipid lowering. Our results show that TaqIB polymorphism modulated the effectiveness of atorvastatin reduction on lipid values, especially on HDL-C and TG (to a lesser degree). Also, in the Low HDL group the effectiveness of reduction of total cholesterol and TG varied according to TaqIB polymorphism. In the High HDL group the \% reduction of LDL-C varied according to I405V polymorphism.

The gene frequencies for the TaqIB and I405V polymorphisms in our study cohort were similar to those reported in other Caucasian $[3,12,13]$ and dyslipidaemic populations [14]. For example, the population in the Regression Growth Evaluation Statin Study (REGRESS) had similar TaqIB allele frequencies with our population (B1: $59 \%$ vs $58.9 \%$ and B2: $41 \%$ vs $41.1 \%$, respectively) [15]. In another study involving Greek dyslipidaemic individuals, the $\mathrm{V}$ allele frequency was $33 \%$ and in Greeks with coronary artery disease $32 \%[8,16]$, all similar to the present study $(34.5 \%)$. 
Table 3. Differences (in mg/dl) in Lipid Profile of the Whole Study Cohort According to I405V or TaqIB Alleles after Atorvastatin Treatment in Low and High HDL Groups

\begin{tabular}{|c|c|c|c|c|c|c|}
\hline & \multicolumn{6}{|c|}{ Low HDL group } \\
\hline $\mathrm{TC}$ & $-100(58)$ & $-120(44)$ & 0.02 & $-103(66)$ & $-112(41)$ & 0.38 \\
\hline TG & $-50(103)$ & $-118(157)$ & 0.05 & $-61(150)$ & $-82(140)$ & 0.63 \\
\hline \multirow[t]{4}{*}{ LDL-C } & $-55(85)$ & $-79(89)$ & 0.28 & $-52(94)$ & $-85(52)$ & 0.12 \\
\hline & \multicolumn{6}{|c|}{ High HDL group } \\
\hline & \multicolumn{3}{|c|}{ CETP TaqIB } & \multicolumn{3}{|c|}{ CETP I405V } \\
\hline & B1 & B2 & $\mathbf{p}$ & $\mathbf{I}$ & $\mathbf{V}$ & $\mathbf{P}$ \\
\hline HDL-C & $-4(12)$ & $-5(14)$ & 0.25 & $-4(12)$ & $-5(14)$ & 0.42 \\
\hline LDL-C & $-78(52)$ & $-88(58)$ & 0.89 & $-84(52)$ & $-86(49)$ & 0.58 \\
\hline
\end{tabular}

All continuous variables are shown as median and interquartile range. Mann-Whitney U statistic was used to compare the continuous variables among the two allele groups. CETP. cholesteryl ester transfer protein, BMI: body mass index, HDL-C: high-density lipoprotein cholesterol, LDL-C: low-density lipoprotein cholesterol, TC: total cholesterol, TG: triglycerides, diff: Difference between value after and value before atorvastatin treatment.

B1: variant allele-carrying genotypes (B1B1, B1B2), B2: variant allele-carrying genotypes (B2B2, B1B2), I: variant allele-carrying genotypes (II, IV), V : variant allele-carrying genotypes (VV, VI). For TC, HDL and LDL, to convert from $\mathrm{mg} / \mathrm{dl}$ to $\mathrm{mmol} / \mathrm{l}$ divide by 38.8 . For TG, to convert from $\mathrm{mg} / \mathrm{dl}$ to $\mathrm{mmol} / \mathrm{l} \mathrm{divide} \mathrm{by} 88.6$.

Concerning the baseline lipid profile, the VV and B2B2 genotypes have been reported to present with higher HDL-C levels $[2,8]$. Similarly, in the present study, the B2B2 genotypes, as well as the B2 allele, were associated with higher HDL-C levels. The IV (rather than the VV) genotype and V allele was associated with higher HDL-C levels. However, no such association was found for the VV genotype which could be attributed to the low number of subjects with this genotype.

Despite the proven efficacy of statins as a primary and secondary prevention for cardiovascular disease, a significant proportion of patients do not achieve LDL-C goals [17]. This could be due to the interindividual variability in the response to statin treatment [18]. In the REGRESS study, pravastatin reduced total cholesterol, LDL-C, and TG levels and increased HDL-C to a similar extent in all 3 TaqIB genotypes [15]. However, in animals study de Haan et al. [19] reported that atorvastatin increased HDL-C by reducing hepatic CETP expression in E3L.CETP mice (APOE*3Leiden mice crossbred with mice expressing human CETP). This fact supported the hypothesis that CETP gene polymorphisms could play an important role in the lipid lowering effectiveness of atorvastatin. Also, van Venrooij et al., who evaluated the cohort $(n=217)$ from Diabetes Atorvastatin Lipid Intervention (DALI) study (frequency of B1 allele similar to our study $57.1 \%$ ), reported that in carriers with the B1B1 genotype, HDL-C levels increased, whereas in B2B2 carriers, atorvastatin had no effect on HDL-C [20]. Poduri et al. [21] found association with reduced LDL-C lowering by atorvastatin and gene polymorphisms involved in lipid metabolism (including CETP gene) in an Indian population.
They compared the wild-allele homozygote genotype vs variant allele carrying heterozygote and homozygote genotypes and found that variant allele-carrying genotype of TaqIB showed greater increase in HDL-C concentrations following atorvastatin therapy and variant allele carrying I405V showed lower reduction in total cholesterol levels. Contrary to our findings, patients involved in their study had coronary artery disease, were mostly men and had median total cholesterol of 204(35) $\mathrm{mg} / \mathrm{dl}$ and HDL-C of 35(9) $\mathrm{mg} / \mathrm{dl}$, while subjects in our study were dyslipidaemic, $30 \%$ were women and had total cholesterol 286(69) $\mathrm{mg} / \mathrm{dl}$ and HDL-C 44(20) mg/dl. Furthermore, Mohrschladt et al. did not find any differences between TaqIB and statin treatment [22]. In a previous study of ours, the TaqIB had no influence on response to treatment with simvastatin opposite to I405V polymorphism, where I allele carriers responded better [8]. In the present study, carriers of B1 allele increased HDL-C levels after atorvastatin therapy, while the carriers of B2 alleles decreased the HDL-C levels. One explanation is that carriers of the B2 allele had higher HDL-C levels at baseline [42(19) $\mathrm{mg} / \mathrm{dl} \mathrm{vs} 48(19) \mathrm{mg} / \mathrm{dl}$, respectively]. In the Low HDL group the B2 carriers responded better to statin therapy (greater reduction of total cholesterol and TGs). Moreover, in the High HDL-C group the II genotype was associated with greater \% reduction of LDL-C and B1B1 genotype with lower reduction of HDL-C after atorvastatin treatment. Possible explanation for this discrepancy may be that another statin was used (atorvastatin instead of simvastatin). Overall, subjects with low HDL-C levels at baseline seem to benefit to a greater extent than those with high HDL-C levels at baseline after atorvastatin treatment. The HDL-C level was significantly increased $(+12.9 \%)$ and TGs were significantly 
decreased $(-38 \%)$ in group with low HDL-C compared with $8.3 \%$ and $-15.2 \%$, respectively in the group with high HDLC. The different response to hypolipidaemic drugs according the HDL-C baseline levels was suggested by our research group since 1995 [7, 23, 24]. At that time, this was only a clinical observation. However, the response to statin treatment is not solely influenced by a single gene polymorphism. Furthermore, the pharmacogenetic studies on association between genes and lipid lowering response to statins are limited [25]. Many factors could contribute to an individual's response such as side effects, gender, age, body mass index, diet, environmental, CETP mass and activity (CETP genotypes may influence both by approximately $5 \%$ to $10 \%$ ) [26], as well as gene-gene interaction. Gene assessment also has cost and time implications which are disadvantages in routine clinical practice. Nevertheless, these disadvantages may become less relevant as technology develops.

\section{CONCLUSIONS}

The results favour the hypothesis that CETP polymorphisms modify the effect of statin treatment and may help to identify subjects who will benefit more from statin therapy. Thus, the prospective identification of subjects who have a diminished or increased response to statins, may improve the risk-to-benefit ratio of statin therapy. However, this is a small study. To clarify the genes contribution to the statin lipid lowering effect more studies involving higher number of individuals are required.

\section{DECLARATION OF INTEREST}

This study was conducted independently; no company or institution supported it financially.

\section{REFERENCES}

[1] Chapman MJ. Therapeutic elevation of HDL-cholesterol to prevent atherosclerosis and coronary heart disease. Pharmacol Ther 2006; 111: 893-908.

[2] Boekholdt SM, Thompson JF. Natural genetic variation as a tool in understanding the role of CETP in lipid levels and disease. J Lipid Res 2003; 44: 1080-93.

[3] Drayna D, Lawn R. Multiple RFLPs at the human cholesteryl ester transfer protein (CETP) locus. Nucleic Acids Res 1987; 15: 4698.

[4] Kuivenhoven JA, de Knijff P, Boer JM, et al. Heterogeneity at the CETP gene locus. Influence on plasma CETP concentrations and HDL cholesterol levels. Arterioscler Thromb Vasc Biol 1997; 17: 560-8.

[5] Szapary PO, Rader DJ. The triglyceride-high-density lipoprotein axis: an important target of therapy? Am Heart J 2004; 148: 211-21.

[6] Liberopoulos EN, Daskalopoulou SS, Mikhailidis DP, et al. A review of the lipid-related effects of fluvastatin. Curr Med Res Opin 2005; 21: 231-44.

[7] Kolovou GD, Fostinis YP, Bilianou HI, et al. Response of highdensity lipoproteins to hypolipidemic drugs according to their initial level. Am J Cardiol 1995; 75: 293-5.

[8] Anagnostopoulou K, Kolovou G, Kostakou P, et al. Pharmacogenetic study of cholesteryl ester transfer protein gene and simvastatin treatment in hypercholesterolaemic subjects. Expert Opin Pharmacother 2007; 8: 2459-63.

[9] Grundy SM, Cleeman JI, Merz CN, et al. National Heart, Lung, and Blood Institute; American College of Cardiology Foundation; American Heart Association. Implications of recent clinical trials for the National Cholesterol Education Program Adult Treatment Panel III guidelines. Circulation 2004; 110: 227-39.

[10] Kolovou G, Anagnostopoulou K, Kostakou P, et al. Association between the TaqIB polymorphism in the cholesteryl ester transfer protein gene locus and postprandial plasma lipoprotein levels in heterozygotes for familial hypercholesterolemia. Clin Chem Lab Med 2007;45: 1190-8.

[11] Gudnason V, Kakko S, Nicaud V, et al. Cholesteryl ester transfer protein gene effect on CETP activity and plasma high-density lipoprotein in European populations. The EARS Group. Eur J Clin Invest 1999; 29: 116-28.

[12] Hannuksela ML, Liinamaa MJ, Kesäniemi YA, et al. Relation of polymorphisms in the cholesteryl ester transfer protein gene to transfer protein activity and plasma lipoprotein levels in alcohol drinkers. Atherosclerosis 1994; 110: 35-44.

[13] Freeman DJ, Griffin BA, Holmes AP, et al. Regulation of plasma HDL cholesterol and subfraction distribution by genetic and environmental factors: associations between the TaqI B RFLP in the CETP gene and smoking and obesity. Arterioscler Thromb 1994; 14: 336-44.

[14] Hassanzadeh T, Firoozrai M, Zonouz AE, Zavarehee A, Paoli M. Taq1B polymorphism of cholesteryl ester transfer protein (CETP) gene in primary combined hyperlipidaemia. Indian J Med Res 2009;129: 293-8.

[15] Kuivenhoven JA, Jukema JW, Zwinderman AH, et al. The role of a common variant of the cholesteryl ester transfer protein gene in the progression of coronary atherosclerosis. The Regression Growth Evaluation Statin Study Group. N Engl J Med 1998; 338: 86-93.

[16] Kolovou GD, Anagnostopoulou KK, Karyofillis P, et al. Cholesteryl ester transfer protein gene polymorphisms and severity of coronary stenosis. Clin Invest Med 2006; 29: 14-9.

[17] Yan AT, Yan RT, Tan M, et al. Contemporary management of dyslipidemia in high-risk patients: targets still not met. Am J Med 2006; 119: 676-83.

[18] Schmitz G, Drobnik W. Pharmacogenomics and pharmacogenetics of cholesterol-lowering therapy. Clin Chem Lab Med 2003; 41: $581-9$.

[19] de Haan W, van der Hoogt CC, Westerterp M, et al. Atorvastatin increases HDL cholesterol by reducing CETP expression in cholesterol-fed APOE*3-Leiden. CETP mice. Atherosclerosis 2008; 197: 57-63.

[20] van Venrooij FV, Stolk RP, Banga JD, et al; DALI Study Group. Common cholesteryl ester transfer protein gene polymorphisms and the effect of atorvastatin therapy in type 2 diabetes. Diabetes Care 2003; 26: 1216-23.

[21] Poduri A, Khullar M, Bahl A, Sehrawat BS, Sharma Y, Talwar KK. Common Variants of HMGCR, CETP, APOAI, ABCB1, CYP3A4, and CYP7A1 genes as predictors of lipid-lowering response to atorvastatin therapy. DNA Cell Biol 2010; 29(10): 629-37. [Epub ahead of print].

[22] Mohrschladt MF, van der Sman-de Beer F, Hofman MK, van der Krabben M, Westendorp RG, Smelt AH. TaqIB polymorphism in CETP gene: the influence on incidence of cardiovascular disease in statin-treated patients with familial hypercholesterolemia. Eur J Hum Genet 2005; 13: 877-882.

[23] Kolovou GD, Daskalova DC, Petropoulos II, et al. Effect of baseline levels on response of high-density lipoprotein cholesterol to hypolipidemic treatment. Am J Cardiol 2003; 92: 1339-42.

[24] Kolovou GD, Cokkinos DV. Low serum levels of high-density lipoprotein cholesterol and hypolipidaemic treatment. Curr Med Res Opin 2002; 18: 265-8.

[25] Mangravite LM, Thorn CF, Krauss RM. Clinical implications of pharmacogenomics of statin treatment. Pharmacogenomics J 2006; 6: 360-74.

[26] Thompson A, Di Angelantonio E, Sarwar N, et al. Association of cholesteryl ester transfer protein genotypes with CETP mass and activity, lipid levels, and coronary risk. JAMA 2008; 299: 2777-88. 